\title{
Reflections on the State of Design Science Research
}

\author{
DOI 10.1007/s12599-014-0317-5
}

\section{The Author}

Prof. Dr. Martin Bichler ( $\varangle)$

Decision Sciences \& Systems

Institut für Informatik

TU München

Boltzmannstraße 3

85748 München

Germany

bichler@in.tum.de

Published online: 2014-02-12

This article is also available in German in print and via http://www. wirtschaftsinformatik.de: Bichler $M$ (2014) Design-Science: Eindrücke von der ICIS 2013. WIRTSCHAFTSINFORMATIK. doi: 10.1007/s11576-0140410-x.

(C) Springer Fachmedien Wiesbaden 2014
At the time of writing this editorial, ICIS 2013 in beautiful Milan has just come to an end. I want to take the opportunity to reflect on the conference, before I briefly introduce the papers in this issue.

For many colleagues in our community ICIS is the primary meeting every year and it attracted a record number of 1537 registered attendees in 2013. For the US American business schools, ICIS serves as a job market and many new PhD students had interviews with faculty members during the conference. The conference spans an amazing breadth of topics and methods including, but not limited to, qualitative, quantitative, and design research. As 10 years have now gone by since the seminal article "Design science in information systems research" by Hevner et al. was published in MIS Quarterly (with more than 4600 citations now), it is interesting to look at the conference from a design science perspective.

The conference started with the ICIS Doctoral Consortium as a pre-conference event and the presentations can be seen as a sample from which one can estimate which methods young academics in IS employ. I should mention that the majority of the 40 student participants were from US universities and that this is not necessarily representative for the rest of the world. Many of the students collected data sets from various online sites including online job markets, financial portals, or crowd-funding platforms and analyzed user behavior or project success. Applied econometrics played a central role in most of these presentations, design research however did not. Depending on the focus of the site analyzed, there was a close connection to labor economics, finance, marketing, or other areas in business. Also, in the program of the main conference quantitative and qualitative methods seemed to outnumber design research by far. Overall, after 10 years of discussion about design science in IS, the number of design science papers was still comparatively small in both the Doctoral Consortium and the ICIS conference.

This should not be seen as criticism towards research that is not design-oriented. Actually, many of the presentations in the Doctoral Consortium and also in the main conference revealed very interesting insights into the online behavior of users or groups of users. I am absolutely convinced that we need to analyze information systems from an economic as well as from a behavioral point of view and that some of the respective questions will even gain importance in our digital world. It is hard for me to even imagine IS nowadays without areas such as Economics of IS or Information and Knowledge Management.

However, I also believe that it would have substantial consequences if we gave up on design research. First, this would impact teaching. If we do not design systems in our research there will be lower incentives but also less expertise to teach topics such as systems design and development. Actually, many $\mathrm{PhD}$ students I talked to at the Doctoral Consortium had virtually no experience in information systems development. Much of the demand for IS students in the industry is driven by the fact that alumni have skills in information systems design and development as well.

Second, we would lose a competitive advantage of IS research over other fields in business and economics. Marketing colleagues also look at user behavior in online shops and colleagues in finance collect data from online investment sites and analyze online investment decisions. This is not to say that we should not do so, but a defining feature of much successful IS research has long been that we also designed systems that we then analyzed. In the analysis of design artifacts, lab experiments, field studies, econometrics, but also qualitative methods all play a role and they actually make the research distinct in comparison to what is typically done in most areas of business and economics. In contrast to much research in computer science, good design research in IS has the advantage of being well grounded in the social sciences. The evaluation of the impact of newly designed artifacts on individuals, groups, and organizations stands out in the methods employed, but also in the understanding of the application domain. Of course, design research needs to contribute new knowledge in a field, beyond solving a real-world problem. It would be a pity if we lost this ability to design and to evaluate 
at a time when this skill set is most needed. Apart from this, helping design the future digital economy is a wonderful opportunity for young academics to make a difference.

Among the many other pre- or post-ICIS workshops, WITS (Workshop on Information Technology and Systems) traditionally has a focus on design research with sessions on data and text mining, social analytics, systems optimization, and recommender systems. Paulo Goes, the Editor-in-Chief of MIS Quarterly, gave a keynote with the title "Looking for Design Science Research in Top-Tier IS Journals. Has anyone seen it?" He reported that only about $5 \%$ of the submissions to MIS Quarterly are actually design science papers and that the segment has, as of yet, not been growing in MIS Quarterly at the speed expected 10 years ago. He called the community for action and advocated that the journal is very open to design-oriented papers with several new editors with a respective background. Of course, most departments at BISE are also very receptive towards design research.

Many design projects originate out of joint projects with industry practitioners. Apart from their academic appeal, good IS design research projects often have a substantial impact on real-world business processes. This is an important contribution of IS to the society, however, there has often been little recognition of these achievements in academia. In 2008, the INFORMS Information Systems Society (ISS) initiated the ISS Design Science Award (http://mis.eller.arizona.edu/events/informs/winners/index.asp).

This year, the BISE journal will co-sponsor the ISS Design Science Award. Several subcommunities and departments in Business and Information Systems Engineering are primarily design-oriented, and it is fair to say that the European IS community with its engineering history actively practiced design research long before the MIS Quarterly article was published. I would like to encourage all of you, who have completed interesting projects with industry partners and a tangible impact on business practice, to submit proposals.

Let me now provide you with a brief guide of the articles in this issue. The first three articles were submitted as a response to the call for research areas in Business and Information Systems Engineering. The paper "Social Knowledge Environments" by Markus Bick et al. describes strategies, management, and processes, utilizing social software systems and tools to enhance knowledge management, and outlines research opportunities in this area. Böhmann et al. outline "Service Systems Engineering" as the systematic design and development of service systems. They suggest design research as well as action research as appropriate approaches leading to innovation in service systems. Finally, the paper "Social Media Analytics" by Stieglitz et al. provides another look at social media and various methods such as text mining, social network analysis, and trend analysis, which allow researchers, but also businesses, to understand customer behavior.

A state-of-the-art article by Diebold et al. discusses "Course Allocation and Stable Matching". The paper has a long history and started out in early 2012 with a project aimed at evaluating stable matching algorithms for assignment problems in a university context. The Nobel Prize in economic sciences in 2012 was then awarded to Lloyd Shapley and Alvin Roth for their work on stable matching, which made this line of research much more prominent. In spite of its popularity more recently, there is still little empirical research. In addition to an up-do-date literature survey, the paper provides results of field studies which allow decision makers to better understand the trade-offs between stable matching mechanisms and simple first-come, first-serve assignments as they are typically used for course allocation.

Finally, Torsten Eymann, Dennis Kundisch, and Jan Recker collected contributions from six German-speaking academics, who spent a considerable part of their career in institutions in the United States or in Australia. The contributions discuss individual experiences abroad, but also after returning to Europe. I found the collection very interesting and delightful to read and hope you will share my opinion. 